\title{
Application of Laparoscopic Radical Cystectomy and Urinary Diversion based on 3D Technique
}

\author{
HUI XU, MINGSHUAI WANG, LIYUAN WU, Q. HE AND N. XING ${ }^{1 *}$ \\ Department of Urology, Beijing Chao-Yang Hospital, Capital Medical University, Beijing 100020, ${ }^{1}$ Department of Urology, \\ National Cancer Center/National Clinical Research Centre for Cancer/Cancer Hospital, Chinese Academy of Medical Sciences \\ and Peking Union Medical College, Beijing 100021, China
}

\section{Xu et al.: 3D Laparoscopic Radical Cystectomy and Urinary Diversion}

\begin{abstract}
The 3D laparoscopic surgery overcomes the lack of depth of field in traditional laparoscopic images, and maximizes the true field of view, which provides great convenience for the development and improvement of this surgical technique. This investigation mainly explored the application of 3D laparoscopy in radical cystectomy and urinary diversion. The clinical data of 7 patients undergoing 3D laparoscopic total cystectomy and urinary diversion were retrospectively analysed. The primary disease and surgical methods were analysed. The success rate of 33 cases was $100 \%$. All patients underwent surgery without any additional incision. There was no open surgery and no perioperative death. The surgical margins were negative. The above patients were followed up for 8-12 months, and no tumour recurrence or metastasis was observed. The 3D laparoscopy restored the true anatomical level and effectively shortened the operation time. The system has the advantages of accurate operation, easy suturing and fewer complications, which reduces radical cystectomy and urinary diversion.
\end{abstract}

Key words: 3D, laparoscopy, cystectomy, urinary diversion

Bladder cancer is the most common malignant tumour in the urinary system. With exposure to more carcinogenic factors, its incidence is increasing year after year ${ }^{[1]}$. For example, smoking not only increases the incidence of bladder cancer, but advances the onset of bladder cancer. Radical cystectomy, regional lymph node dissection and urinary diversion are the gold standard for the treatment of myometrial invasive bladder cancer and high-risk superficial bladder cancer. In the 19th century, the first complete resection of bladder cancer was successfully performed. With the development of medical technology, traditional open surgery is replaced by laparoscopic surgery ${ }^{[2]}$. The patient recovers faster and the hospital stay is shorter. Whether using traditional surgery or laparoscopic surgery, reconstruction of urinary flow after radical cystectomy is important ${ }^{[3]}$. The principle of 3D laparoscopic operation is roughly divided into 3 steps, image collection, image finishing and image display ${ }^{[4]}$. The operator and assistants are in the same polarization state by wearing special 3D glasses and the display screen.

At this time, the person cannot receive other image information but can only receive the image information inside the lens system, so that the observer will generate $3 \mathrm{D}$, the effect is as realistic as looking at the object with both eyes ${ }^{[5]}$. In recent years, 3D laparoscopy technique has been further popularized in clinical practice and it has advantages in suture knotting, hierarchical recognition and fine anatomy, especially in the complex need of fine anatomy such as partial nephrectomy, total cystectomy, radical prostatectomy ${ }^{[6]}$ and reconstruction surgery. More importantly, with the help of 3D laparoscopic techniques, the surgeon can better distinguish the anatomical structure of the obstructive nerve of the iliac vessels and vascularize the nerves and nerves when cleaning the bilateral lymph nodes. Patient prognosis and postoperative tumour staging are critical. This investigation was aimed to investigate the clinical application of 3D laparoscopy in radical cystectomy and urinary diversion.

\section{MATERIALS AND METHODS}

\section{Clinical data:}

A total of 33 cases of patients with bladder tumours from February 2008 to October 2017, which included women, 
aged 37 to 83 y. Pathological biopsy of cystoscopy was diagnosed as transitional cell carcinoma and invasive bladder cancer. There was no extra-bladder infiltration in pelvic CT plain scan and enhancement and MRI. No distant metastasis was found in B-ultrasound, chest plain film and ECT. Urinary tract angiography showed normal bilateral urinary tract development. The patients had good cardiopulmonary function, including 2 cases of mild ventilatory dysfunction and no obvious contraindications for surgery. Six patients underwent ileal neobladder surgery, 17 patients underwent ileal bladder surgery and 10 patients underwent ureter cutaneous ostomy. Oral streptomycin and metronidazole were taken from $3 \mathrm{~d}$ before operation; semisolid food was taken $2 \mathrm{~d}$ before operation and only fluid diet was taken $1 \mathrm{~d}$ before operation; the enema was cleaned and the nasogastric tube was placed before surgery in the morning.

\section{The effectiveness of the 3D laparoscopic approach:}

The advent of laparoscopic techniques has been a big step forward for surgical techniques and laparoscopic surgery has become a trend in surgical development. However, because the traditional laparoscopic image is a monocular visual image, that is, a $2 \mathrm{D}$ image, it is very uncomfortable for surgeons who often operate in stereoscopic field of vision ${ }^{[7]}$. There is no sense of depth and it requires long-term rigorous training to adapt. Intraoperative positioning has to rely on endoscopic instruments that touch the tissue or are identified by the signs on the viewing device may slow the operation, increase the operation time, and may also damage the tissues and organs. A surgeon needs extensive and rigorous laparoscopic training and a steep learning curve to perform laparoscopic surgery safely and skillfully ${ }^{[8]}$. These deficiencies reduce the surgeon's interest in laparoscopic surgery and limit the smooth development of laparoscopic techniques. In recent years, the emergence of 3D laparoscopy made up for these defects ${ }^{[9,10]}$. It restores the $3 \mathrm{D}$ stereoscopic field of view in real vision and the surgical field of view is about 4 times, which is equivalent to operating in the patient's body. It can find the lesions among various organs and then perform precise resection and reconstruction. Therefore, compared to the conventional laparoscopy the damage to blood vessels and nerves can be minimized, bleeding further reduced, surgical complications reduced and the operation time shortened. The choice of laparoscopic beginners for research and comparison shows that compared with traditional laparoscopic surgery, 3D laparoscopic surgery has obvious advantages in operation time and accuracy.

All participants were randomized into 2 groups. One group first underwent 3D laparoscopic basic operations and then performed the same procedure under 2D laparoscopy; the other group was reversed. Each participant requested to complete each operation 8 times, recording the time and number of errors for each operation. Each participant was familiar with each test twice before starting and all participants performed the same sequence of tests with the same test conditions. The definition of skills and related errors for each trial is described below.

Test 1 (pick up test), 5 beans of different sizes were moved from a $5.0-\mathrm{cm}$ diameter disk to a $1.0 \mathrm{~cm}$ out test tube having an opening of $15.0 \mathrm{~cm}$. During the movement, the left hand is required to take the beans and pass them to the right hand. Beans falling during delivery or are not accurately placed in the test tube are regarded as mistakes. Test 2 (paper-cut test), this test involved a paper strip with a width of $1.0 \mathrm{~cm}$ and a length of $12.0 \mathrm{~cm}$ and a black stripe with a width of $3.0 \mathrm{~mm}$ for every 5 equidistance marks. The operator holds the gripper on the left and the scissors on the right. Each participant is required to cut at least half the width along the stripes. If you cut out the stripes, make a mistake. Test 3 (with line needle test), the operator holds the needle holder in the right hand and holds the separation forceps on the left. A needle thread with a length of about $20.0 \mathrm{~cm}$ is sequentially passed through a pre-numbered hole with a diameter of about $3 \mathrm{~mm}$. Each attempt to punch a perforation failure during operation is recorded as a sequential error. Test 4 (stitching and knotting test), A 3-0 long needle suture with a length of $15.0 \mathrm{~cm}$ was used, the simulated incision was sutured, and a surgical knot and two single knots were punched. Each time the needle is not pinched, the winding is wound, and the knotting failure is recorded as an error.

All these test results showed that the operation time of the 3D laparoscopic system was significantly reduced and the error rate was also significantly reduced. The average time for beginners to use 1D and 2D systems for 1 to 4 tests is shown in Table 1 .

Repeated tests for each test showed that beginners' use of 3D systems significantly improved the ability to operate and significantly reduced operation time. The first 3 tests were relatively simple, so the completion time is almost same, and the learning curve is relatively parallel. The 4th knotting test was relatively difficult, the completion time is significantly longer, and the learning 
TABLE 1: AVERAGE OPERATING TIME FOR EACH EXPERIMENT IN 3D AND 2D MODES

\begin{tabular}{lcccc}
\hline Group & Bean experiment (A) & Paper cutting experiment (B) & Needle trace test (C) & Knotting experiment (D) \\
\hline 3D & $48.18 \pm 14.48$ & $70.98 \pm 27.00$ & $123.79 \pm 50.70$ & $174.85 \pm 68.00$ \\
2D & $54.54 \pm 19.25$ & $81.98 \pm 34.02$ & $142.33 \pm 59.62$ & $240.13 \pm 72.14$ \\
P value & 0.000 & 0.000 & 0.030 & 0.000 \\
\hline
\end{tabular}

curve of the $2 \mathrm{D}$ system is also significantly flatter. The average error rate of beginners using $3 \mathrm{D}$ systems is 77.41 times, and that of $2 \mathrm{D}$ systems is 138.64 times. When using $3 \mathrm{D}$ systems, the error rate of beginners is reduced by $44.16 \%$, as shown in fig. 1 .

The results showed that beginners use stereoscopic displays with significant advantages over ordinary $2 \mathrm{D}$ displays. Both the completion time and the number of errors are significantly reduced, especially for relatively complicated operations (line-by-wire test, knotting test), which is more obvious and significantly reduce the learning difficulty. These relatively complex operations require the operator to have more accurate spatial judgment of the operating object, while the use of a stereoscopic stereo display increases the depth judgment, meaning that the operator can perform laparoscopic operations more accurately.

\section{Cystectomy:}

All patients had good cardiopulmonary function and no surgical contraindications. Anaesthesia method was general anaesthesia in the trachea. Prone position was Trendelenburg position. The midline incision was taken and the total cystectomy was performed routinely. The 5 trocar method was adopted. The first puncture point was located at the upper edge of the umbilicus, a trocar with a diameter of $12 \mathrm{~mm}$ was inserted, a $30^{\circ}$ laparoscope was placed, and the other 4 trocars were placed under direct vision; the second and third puncture points were respectively adjacent to the left and right abdominis muscles, and the umbilicus At about 1 to $2 \mathrm{~cm}$, a trocar with a diameter of $12 \mathrm{~mm}$ was inserted. The 4th and 5th puncture points were inserted 2 to $3 \mathrm{~cm}$ above the upper and lower anterior superior iliac spine, and a trocar with a diameter of $5 \mathrm{~mm}$ was inserted. The operator was operated by two trocars on the right side, and the assistant was operated by two trocars on the left side. The bilateral ureters were found and freed across the iliac vessels until the entrance to the bladder was closed, the bilateral ureters were removed, and the ureteral stump was sent to a frozen biopsy. The uterus was first separated under laparoscopy and the cervix was preserved. Bilateral pelvic lymphadenectomy was performed to remove lymph and adipose tissue around the external arteriovenous, internal and external sacral

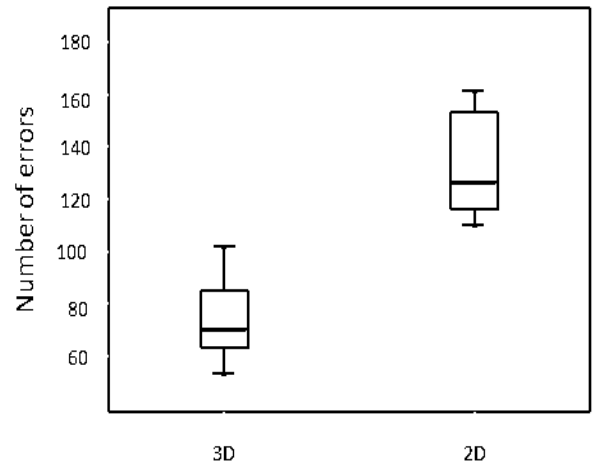

Fig. 1: The entire experiment error count

nerves. The vascular pedicle of the bladder side was separated and disconnected. In the cervix and bladder space, the bladder is separated into the bladder neck, and the peritoneum of the lower abdominal wall is cut. The anterior wall of the bladder was separated into the posterior pubic space. The bladder ligament was separated and cut off, and the urethra was cut off at the bladder neck to completely remove the bladder. A 4 to $5 \mathrm{~cm}$ incision in the midline of the lower abdomen was made and take out the specimen.

\section{Urine flow diversion:}

The first one relies on the action of the anal sphincter to achieve the purpose of controlling urination, but there are many complications, so it has been rarely used. The second is intermittent self-dominant urine by stoma on the abdominal wall. The key factor for its implementation is to rebuild a low-pressure, highcapacity, urine-absorbable or non-reflux storage reservoir. The preferred ileum was used as a storage sac because of its high compliance, which was convenient for operation during operation and easy to take. The rich blood supply is not prone to necrosis. This kind of controlled urinary flow reconstruction skin ostomy has quite a number of surgical methods. As one of them, the storage urinary sac is a surgical method that solves upper urinary tract reflux and achieves the purpose of controlling urine. Surgical orthotopic surgery is complicated, with long operation time and many postoperative complications. The ileal bladder is a representative of orthotopic bladder surgery, but because it does not have an antireflux mechanism, postoperative urine reflux can cause complications 
such as renal insufficiency and pyelonephritis. Later ileal neobladder surgery establishes an antireflux mechanism, but it is prone to stenosis of the input fistula. Whether establish an antireflux mechanism remains still inconclusive, but orthotopic bladder surgery is the closest surgical procedure to normal physiological urination. There is no need to make fistula and regular intermittent urination to improve the quality of life of patients (Table 2).

The ileal neobladder was superior to ileal bladder surgery and ureteral skin ostomy in 4 aspects of quality of life. The quality of life of patients with ileal neobladder was higher. Diversion of the urine flow according to the tumour condition was done. Compared with the primary ileal bladder surgery, three kinds of urinary diversion surgery can maximize the characteristics of physiological urination and improve the patient's postoperative quality of life. The ileal neobladder surgery was preferred in the premise of meeting the indications.

Ileum bladder surgery was performed by removing the free intestinal fistula 15 to $20 \mathrm{~cm}$ long at the end of the ileum 10 to $15 \mathrm{~cm}$ away from the blind and the ileum is only used as a channel, not too long. Separate the mesentery and preserve the blood supply, preferably with two arteries (archal arteries). The contents of the intestine were flushed out with saline, and the intestine was rinsed with an iodophor solution. The proximal end and the distal ileal stump were end-to-end anastomosis above the free intestinal fistula to restore the continuity of the intestine and repair the mesenteric space. Two small orifices were made on the mesangial side of the proximal part of the free ileum, and the ureter and the ileal wound were sutured in a full-thickness with a 4-0 gut.

\section{RESULTS AND DISCUSSION}

All 33 patients had smooth operation. The average operation time was $287(220-410) \mathrm{min}$. The average intraoperative blood loss was $226(50-800) \mathrm{ml}$ and the average blood transfusion volume was $180(0-900) \mathrm{ml}$. Perioperative complications included one case of bladder urethral anastomosis, with enhanced nutritional support treatment and self-healing within $12 \mathrm{~d}$ after surgery. One case of postoperative venous thrombosis of the lower extremity, after the anticoagulant therapy, the thrombus disappeared. All patients in this group were followed up for 10 to $46 \mathrm{mo}$, with an average of 26.4 mo. During the follow-up period, patients survived without tumour recurrence and metastasis. There were
TABLE 2: COMPARISON OF QUALITY OF LIFE SCORES AMONG PATIENTS WITH THREE SURGICAL METHODS

\begin{tabular}{lccc}
\hline Project & Ileal neobladder & Briker & UUCS \\
\hline Physiological aspect & $67.3 \pm 1.7$ & $65.8 \pm 1.6$ & $41.8 \pm 3.6$ \\
Psychological aspect & $70.4 \pm 1.7$ & $62.7 \pm 1.6$ & $25.4 \pm 1.7$ \\
Social relations & $52.5 \pm 3.2$ & $52.5 \pm 3.4$ & $33.5 \pm 4.0$ \\
$\begin{array}{l}\text { Environmental } \\
\text { aspects }\end{array}$ & $61.5 \pm 2.5$ & $61.2 \pm 2.0$ & $34.4 \pm 2.7$ \\
\hline
\end{tabular}

TABLE 3: POSTOPERATIVE URINARY MOTILITY TEST RESULTS IN 33 PATIENTS

\begin{tabular}{lc}
\hline Project & $\begin{array}{c}\text { 12 months after } \\
\text { surgery }\end{array}$ \\
\hline Maximum urinary flow rate $(\mathrm{ml} / \mathrm{s})$ & $13.8 \pm 2.8$ \\
Residual urine volume $(\mathrm{ml})$ & $32.6 \pm 10.8$ \\
$\begin{array}{l}\text { Bladder capacity }(\mathrm{ml}) \\
\begin{array}{l}\text { Bladder pressure during urination } \\
\left(\mathrm{CmH}_{2} \mathrm{O}\right)\end{array}\end{array}$ & $374 \pm 76.8$ \\
$\begin{array}{l}\text { Bladder pressure during filling } \\
\left(\mathrm{CmH}_{2} \mathrm{O}\right)\end{array}$ & $47.5 \pm 5.2$ \\
\hline
\end{tabular}

3 patients with mild urinary incontinence after surgery, gradually relieved after giving biofeedback therapy. One patient developed symptoms of dysuria 10 mo after surgery and multiple indwelling catheters due to urinary retention, after the interval, self-cleaning catheterization. Intravenous urography and cystography were performed 6 mo after operation. There were 2 cases of mild hydronephrosis. After continuous follow-up, there was no significant progress in stagnant water. There was a case of vesicoureteral reflux and the patient had no obvious symptoms but was not treated. The daytime urine control rate was $100 \%$ and the night-time urine control rate was $95.8 \%$. The urodynamic examination was reviewed 12 mo after surgery. The results are shown in Table 3.

Complications occurred within $30 \mathrm{~d}$ after surgery, early complications occurred within 3 mo after surgery and late complications occurred 3 mo after surgery. The complication rate was $61.76 \%$ in the ileal bladder group, $33.33 \%$ in the ileal neobladder group, $29.63 \%$ in the ureter dermal ostomy group, and significantly higher in the ileal bladder group, the other two groups $(p<0.05$; Table 4$)$. There was no significant difference in the incidence of early complications among the 3 groups ( $>0.05$; Table 4 ).

The incidence of late complications in the ileal bladder group was $63.64 \%$, which was significantly higher than that in the ileal neobladder group $(33.33 \%)$ and the ureter dermal ostomy group $(30.77 \%, \mathrm{p}<0.05$; Table 4$)$.

The F7 single $\mathrm{J}$ tube was pulled out of the distal end through the intestine, and the intestine was used. The 
TABLE 4: COMPLICATIONS DURING SURGERY, EARLY POSTOPERATIVE COMPLICATIONS AND POSTOPERATIVE COMPLICATIONS IN THREE GROUPS OF PATIENTS

\begin{tabular}{|c|c|c|c|c|c|c|}
\hline \multicolumn{7}{|c|}{ Complications during surgery } \\
\hline Group & No of cases & $\begin{array}{c}\text { Intestinal } \\
\text { obstruction }\end{array}$ & $\begin{array}{l}\text { Intermittent } \\
\text { diarrhea }\end{array}$ & $\begin{array}{l}\text { Stoma-related } \\
\text { complications }\end{array}$ & $\begin{array}{c}\text { Renal } \\
\text { insufficiency }\end{array}$ & $\begin{array}{l}\text { Urine } \\
\text { leak }\end{array}$ \\
\hline Ileal neobladder & 6 & 0 & 0 & 0 & 0 & 1 \\
\hline Ileal bladder & 17 & 3 & 1 & 2 & 0 & 1 \\
\hline $\begin{array}{l}\text { Ureteral skin } \\
\text { ostomy }\end{array}$ & 10 & 0 & 0 & 1 & 0 & 0 \\
\hline \multicolumn{7}{|c|}{ Early postoperative complications } \\
\hline Group & $\begin{array}{c}\text { Intestinal } \\
\text { obstruction }\end{array}$ & $\begin{array}{l}\text { Stoma-related } \\
\text { complications }\end{array}$ & $\begin{array}{c}\text { Renal } \\
\text { insufficiency }\end{array}$ & $\begin{array}{l}\text { Urine } \\
\text { leak }\end{array}$ & Pneumonia & Pelvic abscess \\
\hline Ileal neobladder & 1 & 0 & 0 & 0 & 0 & 0 \\
\hline Ileal bladder & 2 & 1 & 0 & 1 & 0 & 0 \\
\hline Ureteral skin ostomy & 0 & 1 & 0 & 0 & 0 & 1 \\
\hline Group & $\begin{array}{c}\text { Intestinal } \\
\text { obstruction }\end{array}$ & Pelvic abscess & Stenosis & $\begin{array}{c}\text { Renal } \\
\text { insufficiency }\end{array}$ & Pyelonephritis & $\begin{array}{c}\text { Asymptomatic } \\
\text { hydronephrosis }\end{array}$ \\
\hline \multicolumn{7}{|c|}{ Postoperative complications } \\
\hline Ileal neobladder & 1 & 0 & 0 & 0 & 0 & 0 \\
\hline Ileal bladder & 2 & 0 & 1 & 1 & 1 & 1 \\
\hline Ureteral skin ostomy & 0 & 0 & 2 & 1 & 0 & 1 \\
\hline
\end{tabular}

line fixes it. The outer layer of the anastomosis is reinforced with a small intestine. The proximal end of the intestinal fistula was closed with a 3-0 gut. A straight incision about $3.5 \mathrm{~cm}$ in length was made in the right lower abdomen, and the abdominal incision was made straight, and the skin incision was cut into an elliptical shape. The distal end of the ileal bladder is pulled out from the channel, and after the ileum is fixed, the ileum segment is everted to form a $2 \mathrm{~cm}$ long nipple, and a few needle sutures are used to suture the ileal stump and the skin margin and properly fix the single $\mathrm{J}$ tube, comes with a urine collection bag.

Bladder cancer is a common malignant tumour of the urinary system. Radical cystectomy is the most effective method for curing bladder cancer. Laparoscopic radical surgery for bladder cancer is difficult. The surgeon must be familiar with the anatomical path, skilled operation, ability to handle with various complications during surgery, and the ability to operate the surgical basis. Laparoscopic resection of the bladder is still controversial. Compared with surgery, laparoscopic resection of the bladder for pelvic lymph node dissection is not yet mature. There is no uniform standard cleaning method, so it is difficult to ensure the cleaning effect; time-consuming, for beginners, due to the understanding of anatomical structure and application of laparoscopy the technical level of operation will further extend the operation time (fig. 2).

How to choose urinary flow diversion after radical mastectomy has been paid attention to. The ideal total cystectomy+urinary diversion surgery should be as close

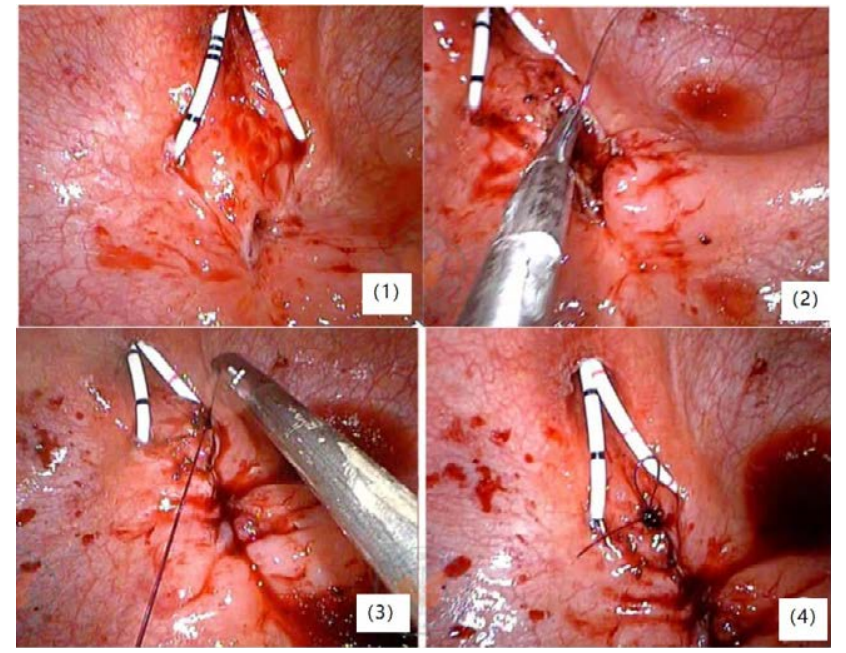

Fig. 2: Operation procedure

(1) Ureteral catheter inserted into bilateral ureter orifice, (2) ureteral catheter is inserted into the bladder from the vagina through the fistula, (3) removal of scar tissue around fistula, (4) the vaginal wall and bladder wall were respectively sutured

as possible to the normal physiological state, namely, high compliance, no reflux, no absorption. Urination can control and protect the upper urinary tract. It has no or only slight influence on renal function and internal environment. The operation is simple, the long-term effect is reliable, and the quality of life of the patient is not affected as much as possible. A large number of studies have shown that in situ controlled ileal bladder surgery is the most ideal bladder replacement surgery, which has good urine storage and urination function, low pressure in the storage urinary sac and high quality of postoperative life. In this group of patients, the ileum and sigmoid colon were used for in situ-controlled bladder surgery. The results showed that the pressure 
of the ileal bladder was lower than that of the sigmoid bladder, and the compliance was good. However, the operation of the sigmoid bladder surgery was simpler than the ileal bladder surgery. In situ controlled ileal bladder surgery is the most ideal method of urinary diversion, but not all patients with cystectomy are suitable for this procedure. Although there are many different surgical methods for urinary diversion, the surgical indications are same. However, a correct and comprehensive comparison among various surgical procedures requires further randomized multi-center study to confirm that the principle of selection should not be blind. In addition, the growth site, the patient's general condition, the patient's will are determined.

The way to establish the urinary outflow tract is divided into uncontrollable and controllable urinary diversion, orthotopic bladder surgery. Two cases of uncontrollable urinary diversion were implemented in the early 20th century. By the middle of the 20th century, this surgical procedure was further improved and popularized. It was further developed into ileal bladder surgery, which was once the most widely used uncontrolled urine flow worldwide. The operation of diversion is easier, and complications are further reduced. However, it is necessary to make a fistula of the abdominal wall, and clean the mouth, so it is easy to be complicated with a narrow mouth and infection. Due to the existence of the mouthwash, it is very troublesome for patients to exercise, engage in social activities, their work and life. The ureteral skin ostomy has the advantages of simple operation, short operation time, no interference with the function of the digestive tract, and quick recovery after operation. However, due to the ureteral blood supply problem and the small diameter of the ureter, the end of the ureter is prone to necrosis, stenosis and urinary tract infection. It is suitable for patients with gastrointestinal diseases, high-risk bladder cancer patients, patients with short life expectancy and poor physical condition who cannot tolerate other operations. Controllable urinary diversion is divided into two types.

In situ ileal neobladder; it usually located in the proximal end of the sigmoid colon. Because the colon will shrink after the break, it is appropriate to cut the intestine section $8 \sim 20 \mathrm{~cm}$ long. Under normal circumstances, the sigmoid bladder should be made in the left abdomen. The intestinal lumen of the free intestinal fistula was washed with normal saline, and the proximal end of the intestinal segment was closed with a 2-0 gut suture. Pulling the distal end of the intestine to the stoma, it can be found that the mesenteric band needs to be rotated 180 degrees in a clockwise direction. The blind end of the intestine should be fixed near the bifurcation of the aorta, where the stroke of the two ureters is close. The appropriate site for ureteral sigmoid bladder anastomosis should be selected. The distal mucosa of the distal intestine is turned into a papillary shape, and an elliptical incision is made in the left lower abdomen. The aponeurosis layer is cut by the cross, and the distal end of the colon is sutured to the left lower abdominal wall.

Ureteral skin ostomy, two inferior oblique incisions were made to separate the lower and middle ureters of the ureter in the retroperitoneum, and the blood supply was preserved. Close the bladder with right-angle vascular forceps to clamp the ureter, cut it over the forceps, place the F7 single $\mathrm{J}$ tube, suture the single $\mathrm{J}$ tube with suture, fix it at the ureteral end, and directly pull the ureter end. Incision in the lower abdomen, the end of the bilateral ureter and the cavity were turned out to form a nipple, and the urine bag was directly collected to collect urine.

Laparoscopic total cystectomy is suitable for high-risk patients and its complications are closely related to urinary diversion. 3D laparoscopic technique improves the perception of depth by laparoscopic surgeons. This is impossible for 2D visual effects. On a 2D screen, organs, tissues, and blood vessels that are originally in a hierarchical relationship appear on the same plane. Loss of depth and visual dislocation may lead to prolonged operation time, increased bleeding volume, and even increased complications, which affect the surgical outcome. The 3D laparoscopic system has good depth perception and spatial orientation, which can restore the true field of view, thus shortening the operation time, improving the operation efficiency, reducing the occurrence of bleeding and complications. 3D laparoscopy can improve the accuracy of the operation and further improve the quality of operation. In summary, for women with bladder cancer, laparoscopic total cystectomy+orthotopic ileal bladder surgery based on 3D technology is safe and feasible. It has the advantages of less trauma, less bleeding, and fewer surgical complications. In situ ileal nanovesicle urinary flow diversion can well protect the patient's urinary function and improve the quality of life of patients.

\section{REFERENCES}

1. Chang SS. Re: Comparing Open Radical Cystectomy and Robot-Assisted Laparoscopic Radical Cystectomy: A Randomized Clinical Trial. J Urol 2015;194(5):1232-3.

2. Fontana PP, Gregorio SA, Rivas JG, Sánchez LC, Ledo JC, 
Gómez Á, et al. Perioperative and survival outcomes of laparoscopic radical cystectomy for bladder cancer in patients over 70 years. Cent European J Urol 2015;68(1):24-9.

3. Hermans TJ, Fossion LM. What about conventional laparoscopic radical cystectomy? Cost-analysis of open versus laparoscopic radical cystectomy. J Endourol 2014;28(4):410.

4. Li CC. Minimal incisions for laparoscopic radical cystectomy with extracorporeal-assisted urinary diversion. Urol Sci 2015;26(2):91-94.

5. Shrivastava N, Nayak B, Dogra P, Kumar R, Singh P. Robotassisted laparoscopic radical cystectomy with extracorporeal urinary diversion: Initial experience and outcomes. Indian $\mathrm{J}$ Urol 2018;34(2):122-6.

6. Elhoseny M, Hassanien AE. Mobile Object Tracking in Wide Environments Using WSNs. In: Elhoseny M, editor. Dynamic Wireless Sensor Networks. Studies in Systems, Decision and Control. Vol 165. Cham, Switzerland: Springer; 2019. p. 3-28.

7. Shi XH, Zheng ZG, Zhou YL, Jin H, He LG, Liu B, et al. Graph Processing on GPUs: A Survey. ACM Comput Surv 2018;50(6):35.
8. Zhang B, Wang X, Zheng Z. The optimization for recurring queries in big data analysis system with MapReduce. Future Gener Comput Sys 2017;87:549-56.

9. Yao SH, Zheng ZG, Wang T, Guan QF. An efficient joint compression and sparsity estimation matching pursuit algorithm for artificial intelligence application. Future Gener Comput Sys 2018;86:603-13.

10. Zheng Z, Huang T, Zhang H, Shenli S, Jinming W, Ping W. Towards a resource migration method in cloud computing based on node failure rule. J Intell Fuzzy Sys 2016;31(5):2611-8.

This is an open access article distributed under the terms of the Creative Commons Attribution-NonCommercial-ShareAlike 3.0 License, which allows others to remix, tweak, and build upon the work non-commercially, as long as the author is credited and the new creations are licensed under the identical terms

This article was originally published in a special issue: Special issue on "Drug Development and Human Health in China"

Indian J Pharm Sci 2020:82(1)spl issue2;14-20 